\author{
Military Technical College \\ Kobry El-kobbah, \\ Cairo, Egypt
}

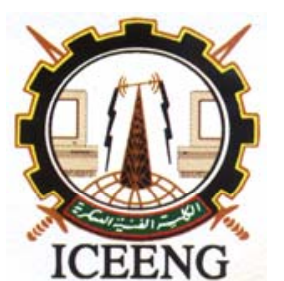

\section{$5^{\text {th }}$ International Conference on Electrical Engineering ICEENG 2006}

\title{
DESIGN OF BRUSHLESS DC POSITION SERVO SYSTEMS USING ADAPTIVE FUZZY CONTROLLER
}

\author{
A. Kamel* and A.E.Abdalla**
}

\begin{abstract}
This paper deals with brushless DC position control systems of unknown external load disturbances and plant parameter variations .Such systems have a very complex dynamic characteristics and highly nonlinearity, a conventional linear control design may not assure satisfactory requirements. One promising method to improve the dynamic response of such systems is adaptive fuzzy controller (AFC) which has been proposed. The proposed AFC is inherently robust, and is based on simple rules that are derived from engineering and experimental results. Simulation results show that the proposed approach can achieve accurate velocity/position servo tracking in the presence of load disturbance and plant parameter variations. Excellent flexibility and adaptability as well as high precision and good robustness are also obtained by the proposed strategy.
\end{abstract}

\section{KEY WORDS}

Brushless DC- Adaptive fuzzy controller (AFC)- Performance measure (PM).

\section{INTRODUCTION}

Brushless dc motors are highly efficient, reliable and easy to control. Their favorable characteristics, higher torque/weight ratio, increased operating speed, lower rotor moment of inertia, better heat dissipation, smaller size and lower weight make them suitable for use in most servo applications. Actuations, robotics, and guided manipulations are the most of these applications where precise movements are required $[1,2]$. The brushless dc motors, also, have a low volume-to torque ratio. This makes them an attractive candidate for applications, which have traditionally employed hydraulic systems [3]. The brushless dc motors, also have many advantages, the most obvious of these is replacement the functions of commutator and brushes by solid- state switches, and maintenance-free motors were realized.

The elimination of brush maintenance and/or replacement makes this type of motor better suited for remote application where maintenance is difficult [2].

* Air Defense College, Alexandria, Egypt.

** Military Technical College, Cairo, Egypt. 


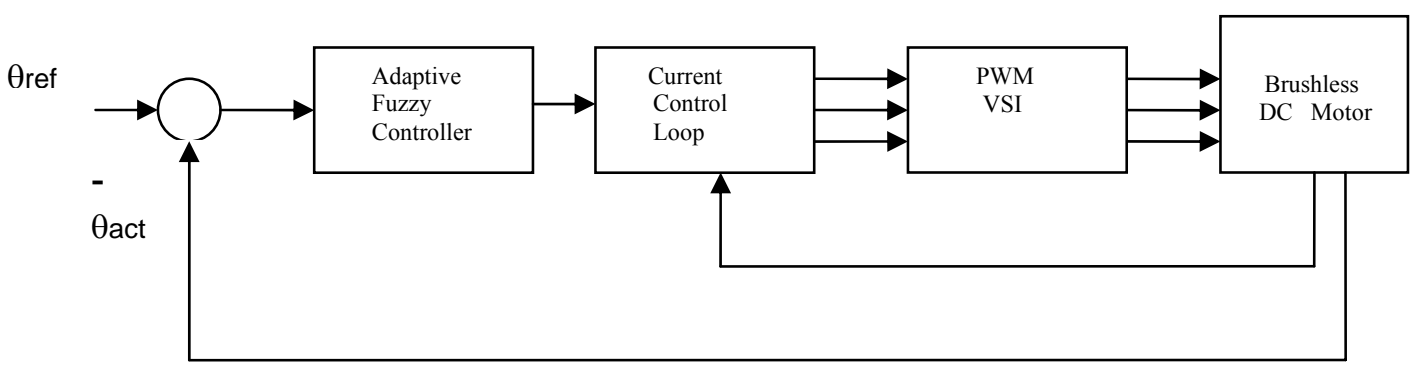

Fig.1 The Block diagram of brushless dc motor position servo system.

The over all proposed control scheme for a brushless dc motor velocity/position servo control system is illustrated in Fig.1. It has a sinusoidal current- controlled pulse width modulated (PWM)voltage source inverter (VSI)which is widely applied in high- performance dc drives. The outer control loop is designed to achieve a fast and accurate servo-tracking response under load disturbance and plant parameter variations [4]. Position and speed tracking of brushless dc motors require high degree of accuracy. However such requirements are usually difficult to achieve by using traditional controllers under load disturbance and plant parameter variations. So, adaptive control becomes necessary for obtaining satisfactory behavior of servo systems [5].

\section{MODELING OF BRUSHLESS DC SERVO MOTOR}

The brushless dc motor is a three phase permanent-magnet synchronous machine with sinusoidal back electromotive force (EMF). The relation between voltage and current for the stator windings as follows [6].

$$
\left[\begin{array}{l}
v_{a s} \\
v_{b s} \\
v c s
\end{array}\right]=\left[\begin{array}{ccc}
R_{s} & 0 & 0 \\
0 & R_{s} & 0 \\
0 & 0 & R_{s}
\end{array}\right]\left[\begin{array}{l}
i_{a s} \\
i_{b s} \\
i_{c s}
\end{array}\right]-\left[\begin{array}{ccc}
L_{s} & 0 & 0 \\
0 & L_{s} & 0 \\
0 & 0 & L_{s}
\end{array}\right] d / d t\left[\begin{array}{c}
i_{a s} \\
i_{b s} \\
i_{c s}
\end{array}\right]-\omega_{r} k_{e}\left[\begin{array}{c}
\sin \left(\theta_{r}\right) \\
\sin \left(\theta_{r}-2 \pi / 3\right) \\
\sin \left(\theta_{r}+2 \pi / 3\right)
\end{array}\right]
$$

where

$$
\begin{array}{ll}
v_{a s}, v_{b s}, v_{c s} & \text { the applied stator voltages; } \\
i_{a s}, i_{b s}, i_{c s} & \text { the applied stator currents; } \\
R_{s} & \text { the resistance of each stator winding; } \\
L_{s} & \text { the inductance of stator winding; } \\
\omega_{r} & \text { the electrical rotor angular velocity; } \\
\theta_{r} & \text { the electrical rotor angular displacement; } \\
k_{e} & \text { the emf constant. }
\end{array}
$$

The electromagnetic torque can expressed as:

$\mathrm{T}_{\mathrm{e}}=\mathrm{k}_{\mathrm{t}}\left[\mathrm{i}_{\mathrm{as}} \sin \left(\theta_{\mathrm{r}}\right)+\mathrm{i}_{\mathrm{bs}} \sin \left(\theta_{\mathrm{r}}-2 \pi / 3\right)+\mathrm{i}_{\mathrm{cs}} \sin \left(\theta_{\mathrm{r}}+2 \pi / 3\right)\right]$

While the torque, speed, and position may be related by:

$\mathrm{Te}=\mathrm{J}_{\mathrm{m}}(2 / \mathrm{P}) \mathrm{d} \omega_{r} / \mathrm{dt}+\mathrm{B}_{\mathrm{m}}(2 / \mathrm{P}) \omega_{r}+\mathrm{T}_{\mathrm{L}}$ 


$$
\begin{aligned}
\theta_{r} & =\int \omega_{r \mathrm{dt}} \\
\omega_{m} & =\omega_{r}(2 / \mathrm{P})
\end{aligned}
$$

where

$\begin{array}{ll}\mathrm{k}_{\mathrm{t}} & \text { the current constant; } \\ \mathrm{P} & \text { the number of poles; } \\ \mathrm{J}_{\mathrm{m}} & \text { the inertia of rotor; } \\ \mathrm{B}_{\mathrm{m}} & \text { the damping coefficient; } \\ \mathrm{T}_{\mathrm{L}} & \text { the load disturbance; } \\ \omega_{m} & \text { the mechanical angular velocity of the rotor. }\end{array}$

\section{ADAPTIVE FUZZY CONTROLLER (AFC)}

Controller adaptation provides robustness for time-varying behavior or non-linearity of the process to be controlled. Adaptation can also provide auto tuning of a controller of which the design is based on a model of the process. The proposed AFLC is a self tuning fuzzy logic controller in which the FLC modifies the fuzzy set definition or the scaling factors. By modifying fuzzy set definition, the fuzzy set definition is changed in response according to a number of different performance measures, such as the average square error. By modifying the scaling factors the controller input and output values are mapped into different universe of discourse of the fuzzy set definition [7].

\section{Assumptions in a Fuzzy Logic System Design}

Six basic assumptions are commonly made whenever a fuzzy logic-based control policy is selected. These assumptions are outlined below [8,9]:

1-The plant is observable and controllable: State input and output variables are available for observation and measurement or computation.

2-There exists a body of knowledge in the form of expert production linguistic rules, engineering common sense, intuition, or analytic model that can be fuzzified and rules be extracted.

3-A solution exists.

4-The monitor engineer is looking for a good solution and not necessarily the optimum one.

5-The desired design of a controller must depend on the best available knowledge and within an acceptable precision range.

6-Problems of stability and optimality are open problems.

\section{Procedures for Design Fuzzy Logic Controller}

In general the design procedure goes through the following phases. It is required to:

a)Find appropriate fuzzy sets for all possible input and possible output states to drive the system toward a desired state.

b)Find a set of rules to have mapping between the input and the output fuzzy sets.

c)Associate numerical input values to the system with corresponding elements of the input fuzzy set along with membership values.

d)Find a numerical value to drive the system, when the output fuzzy set with corresponding membership values is given. 
In the proposed positioning servo system the fuzzy input vector comprises the following variables:

$\mathrm{e}(\mathrm{k})=\theta_{\text {ref }}(\mathrm{k})-\theta_{\text {act }}(\mathrm{k})$

$\operatorname{ce}(\mathrm{k})=\mathrm{e}(\mathrm{k})-\mathrm{e}(\mathrm{k}-1)$

where
$\mathrm{e}(\mathrm{k}) \quad$ is the error at $\mathrm{k}^{\text {th }}$ sampling interval
ce(k) is the change of error at $\mathrm{k}^{\text {th }}$ sampling interval
$\theta_{\text {ref }}(\mathrm{k}) \quad$ is the reference position at $\mathrm{k}^{\text {th }}$ sampling interval
$\theta_{\text {act }}(\mathrm{k}) \quad$ is the motor shaft position at $\mathrm{k}^{\text {th }}$ sampling interval

The output of the fuzzy controller is the control voltage and is defined as:

$\mathrm{U}_{\mathrm{c}}(\mathrm{k})=\mathrm{U}_{\mathrm{c}}(\mathrm{k}-1)+\mathrm{GU}^{*} \Delta \mathrm{U}_{\mathrm{c}}(\mathrm{k})$

where

$\Delta \mathrm{U}_{\mathrm{c}}(\mathrm{k}) \quad$ is the output signal of fuzzy controller at $\mathrm{k}^{\text {th }}$ sampling interval

$\mathrm{GU} \quad$ is the gain factor of the fuzzy controller

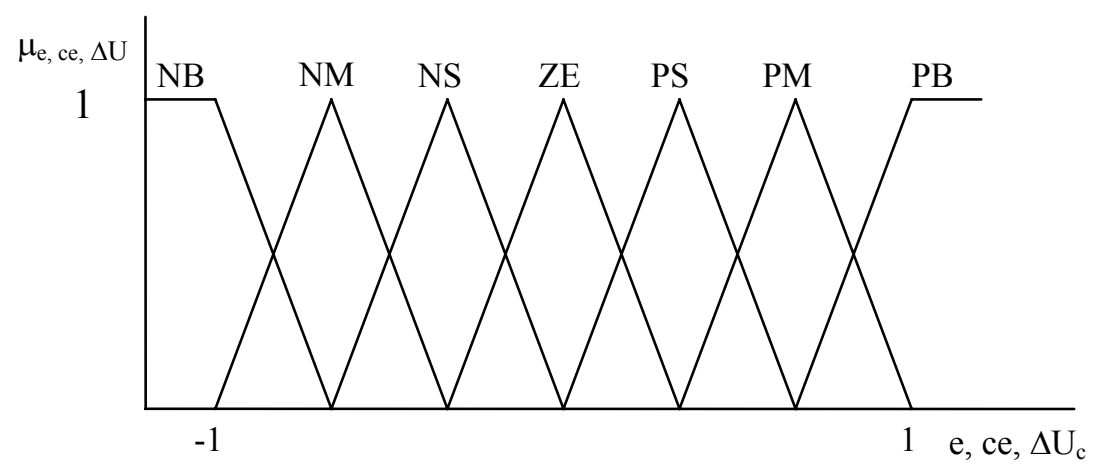

Fig. 2.Membership function for e, ce, $\Delta \mathrm{U}_{\mathrm{c}}$

The membership classes for the input variables $\mathrm{e}(\mathrm{k})$ and ce $(\mathrm{k})$, and the output variable $\Delta \mathrm{Uc}(\mathrm{k})$ are shown in Fig.2. As shown in this figure, the universe of discourse (UOD) for both inputs and outputs is divided into seven fuzzy subsets: NB(Negative Big), NM (Negative Medium), NS(Negative Small), ZE (Zero) PS(Positive Small), PM (Positive Medium), PB(Positive Big). The UOD cover a wide range of positive and negative change of the variables $\mathrm{e}(\mathrm{k})$, ce(k) and $\mathrm{Uc}((\mathrm{k})$. The values of $\mathrm{e}(\mathrm{k})$, ce $(\mathrm{k})$, and $\mathrm{Uc}(\mathrm{k})$ are normalized. Table 1 depicts the output decodingrule which represents the output control signal $\Delta \mathrm{Uc}(\mathrm{k})$ for all combinations of input variables.

The rule assignment table is designed using human expertise to generate the output rule when knowing the input rule. For example: if e $(\mathrm{k})$ is NB and ce(k) is NB then the output rule NB. 
Table 1. Rule base for the position controller

\begin{tabular}{|l|c|c|c|c|c|c|c|}
\hline ee & NB & NM & NS & ZE & PS & PM & PB \\
\hline NB & NB & NB & NB & NB & NM & NS & ZE \\
\hline NM & NB & NB & NB & NM & NS & ZE & PS \\
\hline NS & NB & NB & NM & NS & ZE & PS & PM \\
\hline ZE & NB & NM & NS & ZE & PS & PM & PB \\
\hline PS & NM & NS & ZE & PS & PM & PB & PB \\
\hline PM & NS & ZE & PS & PM & PB & PB & PB \\
\hline PB & ZE & PS & PM & PB & PB & PB & PB \\
\hline
\end{tabular}

\section{Scaling factors FLC technique}

Altering the scaling factors (SF) changes the classification of the process variables. If the real values of the input variables range for example from -200 to +200 and so need to be scaled, for example, the input value is multiplied by a scaling factor of 0.005 , the input is mapped to the universe of discourse that is shown in Fig. 2. In this case as input value of 100 is classified as BIG. Altering the scaling factor changes the classification of input value. For example, with scaling factor of 0.0025 a value of 100 is now classified as MB, as shown in Fig. 2. This reduces the sensitivity of the controller to the input. So, scaling factors are similar to gain tuning in standard PID controllers. The used technique automatically increases the controller gain once the operating point was reached by altering the scaling factors for the error and the change of error. The performance measure is taken as average of the squared error over the previous three sampling times [7]. It is called the performance measure $P M$, which is defined as:

$$
P M=\frac{1}{3} \sum_{i=1}^{i=3 T_{s}} e_{i}^{2}
$$

where

Ts is the sample time.

$e \quad$ is the error (difference between the command value and the measured value).

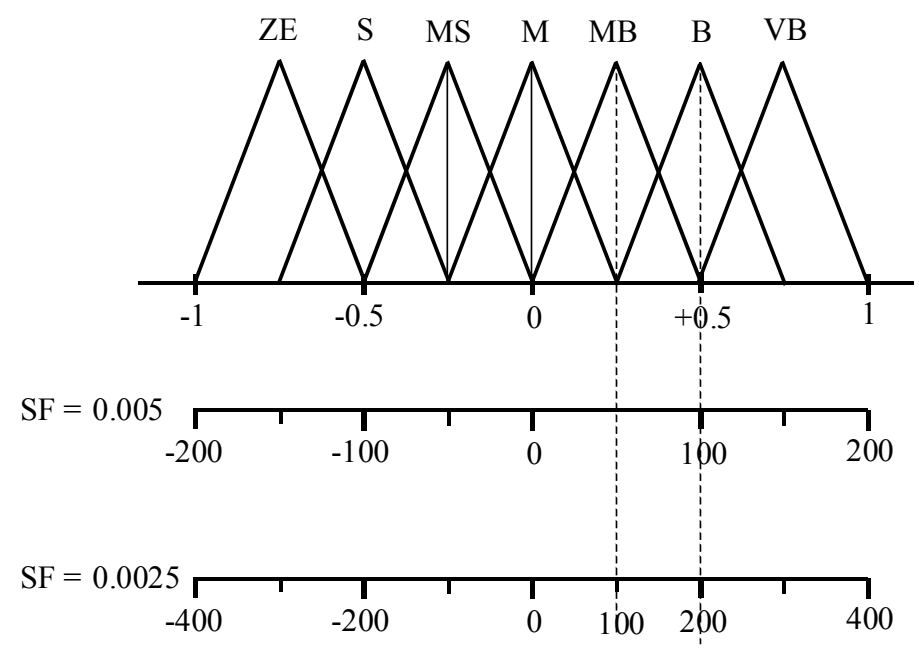

Fig. 3. The effect of altering the scaling factor 
At the sample time, Ts, a scaling factor modifier, CK, is calculated as function of the performance measure, $P M$, according to the set of linguistic fuzzy rules:

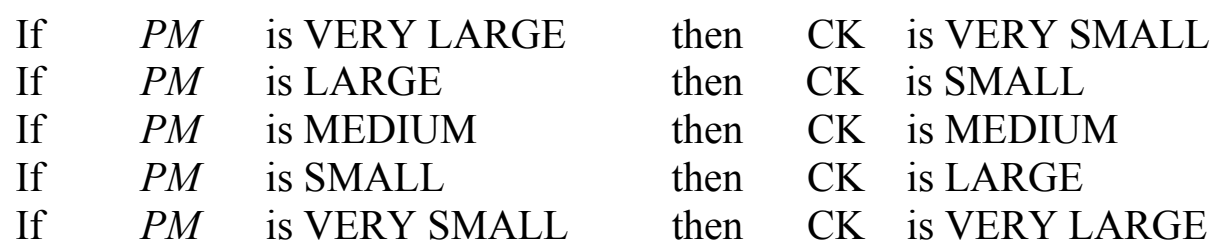

For improving the dynamic performance of the brushless dc motors servo systems, the scaling factors for the error $(\mathrm{Ge})$, change of error (Gee) and the controller output $G_{u K}$ are then calculated via:

$$
\begin{aligned}
& G_{e K}=G_{e o}+C_{K} * G_{e o} \\
& G_{c e K}=G_{c e o}+C_{K} * G_{c e o} \\
& G_{u K}=G_{u o}+C_{K} * G_{u o}
\end{aligned}
$$

where Geo, Gceo and Guo are fixed initial values, and determined experimentally.

These rules for CK can be implemented in a fuzzy way. The rules have the effect of increasing the controller gain by increasing the scaling factors. As the average squared error decreases, the process is maintained around its set-point.

\section{The Adaptation Process}

The adaptation process returns the controller parameters to match the current process characteristics. It involves two extra components on top of the classical fuzzy controller: The performance measure $(\mathrm{Pm})$ that indicates how well the controller is controlling, and the adaptation mechanism that uses information from Pm to adapt the controller parameters and so adapts the controller to the variation of system parameters and loading conditions.

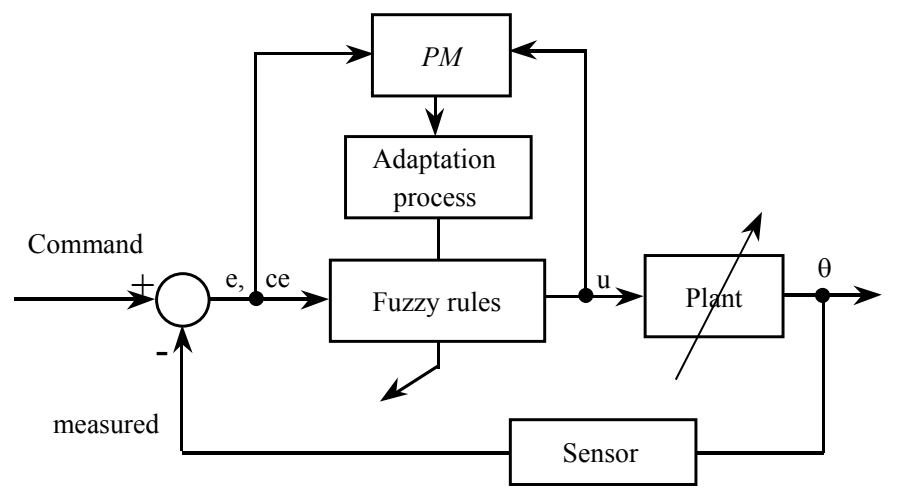

Fig. 4.The block diagram of the adaptive FLC.

The scaling factors (Ge), (Gce) and $G_{u K}$ will be altered to modify the controller performance. This is done by using a Pm table to determine the performance in terms of error and change in error at every sampling time. If the performance is unsatisfactory, then the fixed initial scaling factor values (Geo), (Gceo) and $G_{\text {ио }}$ are changed to a new values equal to $\mathrm{CK}^{*} \mathrm{Geo}, \mathrm{CK} * \mathrm{Gceo}$, 
and $\mathrm{CK}^{*} G_{u o}$ where $\mathrm{CK}$ is the scaling factor modifier, and is calculated as a function of $P M$ according to a set of "IF THEN" fuzzy rules as mentioned before. Fig.4 illustrates the block diagram of adaptive fuzzy controller, while table 2 indicates the fuzzy rules of Pm. Figs. 5 and 6 show the normalized membership function of Pm and CK, are obtained respectively[7,8,9] .

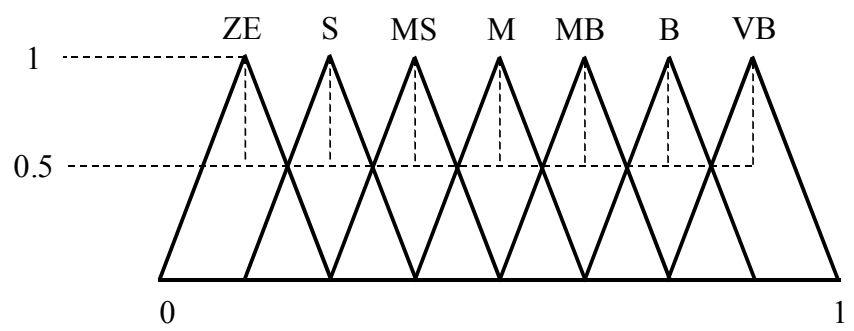

Fig.5.The normalized membership function for $P M$.

Table 2. The $P M$ fuzzy tuning rules for $\mathrm{CK}$.

\begin{tabular}{|c|c|c|c|c|c|c|c|}
\hline$P M$ & ZE & S & MS & M & MB & B & VB \\
\hline $\mathrm{CK}$ & ZE & B & MB & M & MS & S & VS \\
\hline
\end{tabular}

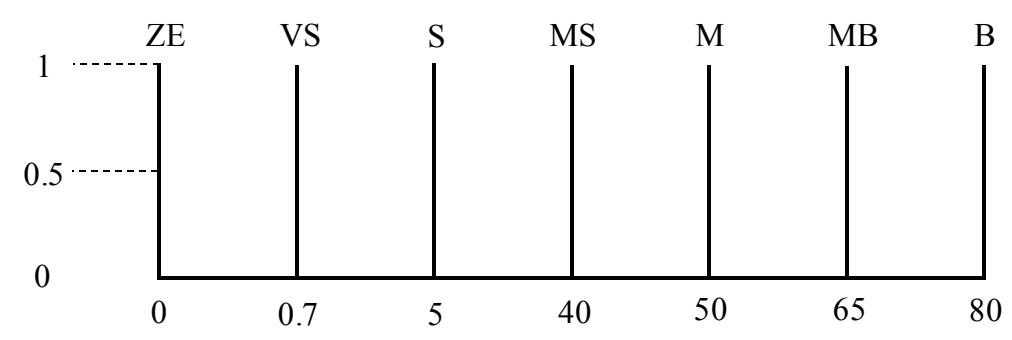

Fig.6.The singleton membership function for CK.

\section{THE COMPUTED RESULTS}

For verifying the effectiveness of the proposed controller, PID controller and conventional fuzzy controller are compared with AFC. Different types of trajectories are introduced to the system also the mechanical load is disturbed. Fig.7 shows the performance of the system for step input under no variation of system parameters, while Fig.8 illustrates the response of the system under load disturbance. It is obvious that AFC has the best response over PID controller and conventional Fuzzy controller, where the response time is short, no over shot, and it has no final error.

For demonstrating the robustness of the proposed controller, a fast sinusoidal is introduced as shown in Fig.9. The position tracking error without variation in load condition is investigated in Fig.10. Fig. 11 investigates the position tracking error when the load is exceeded by $30 \%$.

Fig. 12 shows the wide position tracking trajectory, while Fig.13 investigates the position tracking error without variation of system parameters and Fig.14 displays the tracking error when the load is disturbed. It is clear that AFC offers good position tracking accuracy compared with both PID controller and conventional Fuzzy controller. 


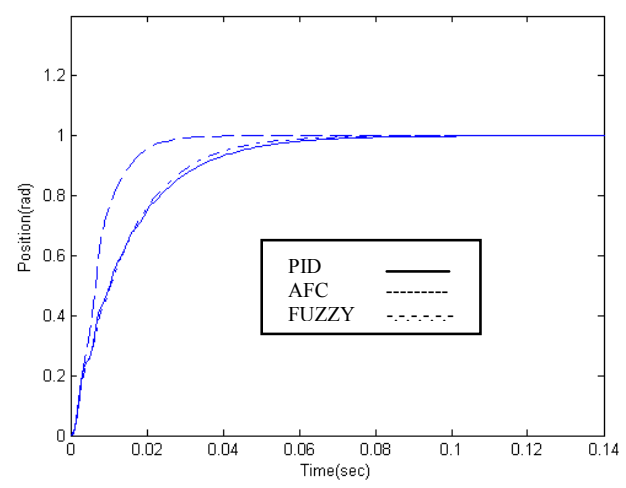

Fig.7. The response of the system without variation in system parameters.

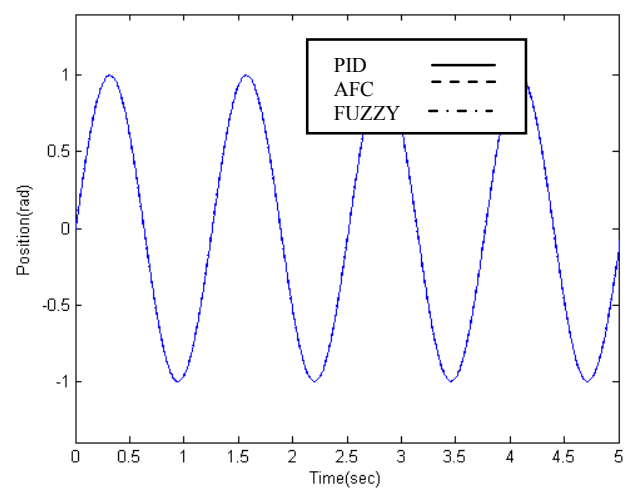

Fig.9.The fast sinusoidal trajectory

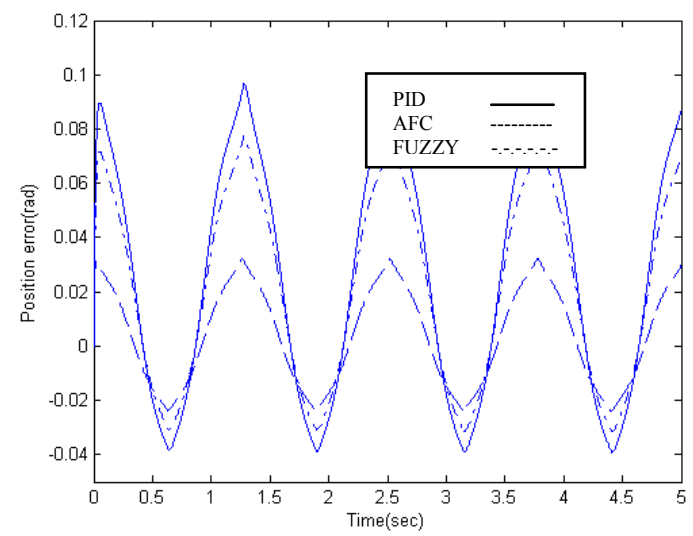

Fig.11. The position tracking error with load disturbance

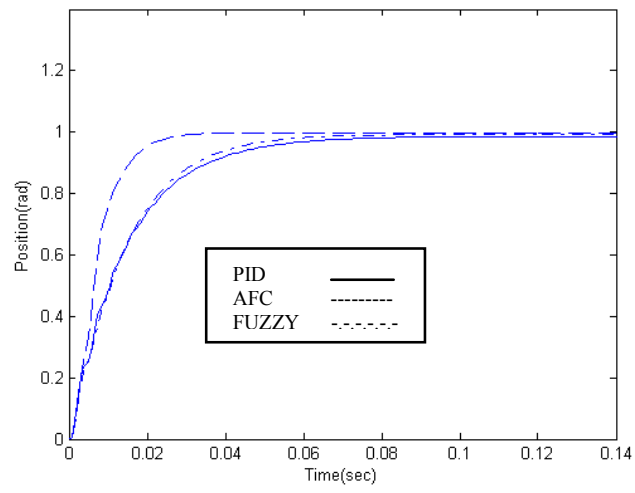

Fig.8. The response of the system under load disturbance.

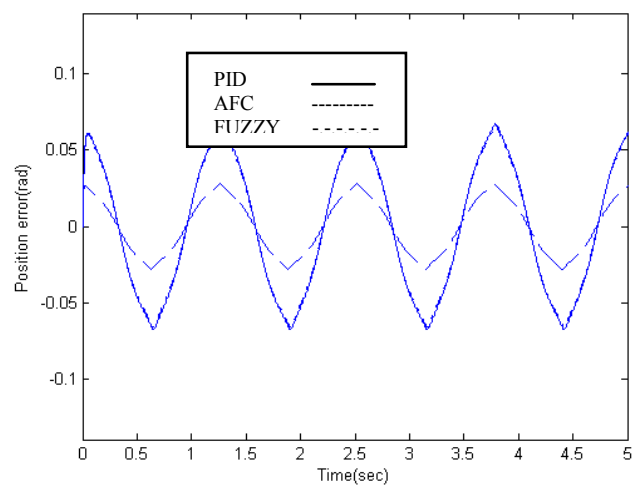

Fig.10.The position tracking error without variation in load

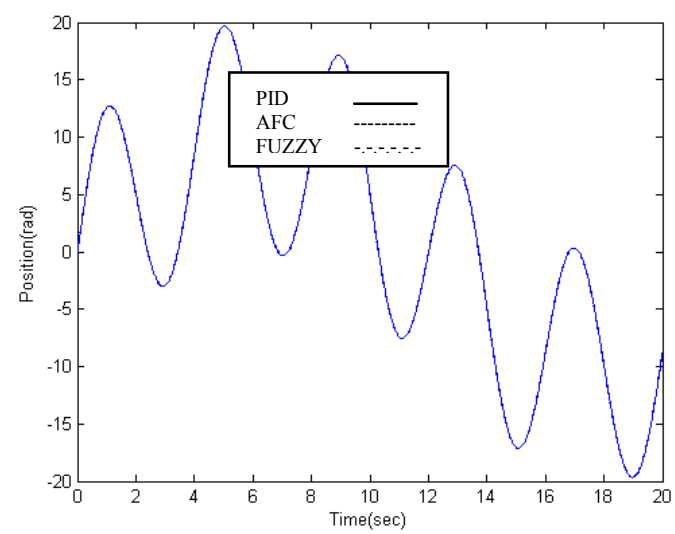

Fig.12. The wide position tracking trajectory 


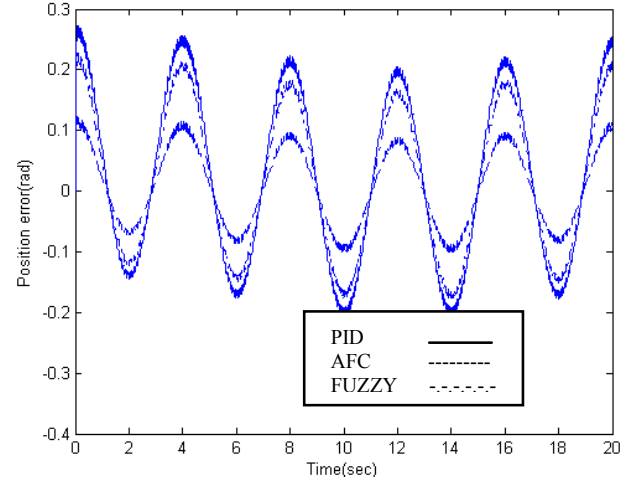

Fig.13. The response of the system without variation in system parameters

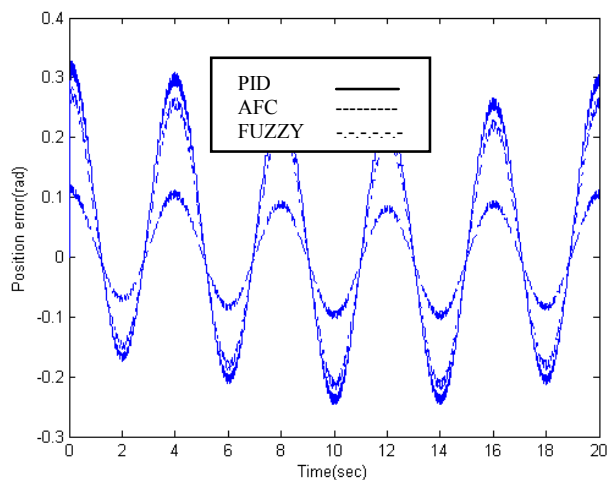

Fig.14. The response of the system under load disturbance

\section{CONCLUSIONS}

In this paper AFC is presented for position control of servo system with brushless dc motor. The simulation results indicate that AFC offers effectiveness, robustness, and good accuracy for position tracking. Compared with PID and conventional fuzzy controller, AFC can not only obtain better adaptive capacity under variation of system parameters or load disturbance, but also get better control accuracy in a situation of change the input trajectory.

\section{REFERENCES}

[1] Ahmed Rubaai, and M.D.Kankam, "Experimental Evaluation of Fuzzy Logic -Based Controller for High performance DC motor Drives," Industry Applications conference, 2000 . Conference Record of the 2000 IEEE Vol.2, 8-12 Oct.2000 page(s):1299-305.

[2] Xia Chanliang, Guo Peijan, ShiTinagna, and Wang Mingchao, "Speed Control of Brushless DC Motor Using Genetic Algorithm Based Fuzzy Controller," Proceedings 2004 International Conference of Intelligent Mechatronics and Automation, on Aug.26-31, 2004, page(s):460-464.

[3] N.A. Demardash and T.Nehl, "Dynamic Modeling of Brushless DC Motors for Aerospace Actuation," IEEE Trans.Aerospace and Elect.System, pp.811-821, Nov.1980.

[4] T.L.Chern and Y.C. Wu," Design of Brushless DC Position Servo SystemsUsing Integral Variable Structure Approach," Electrical Power Applications,IEE Proceedings-B, vol. 140, Issue 1,Jan.1993 page(s):27-34.

[5] C.K.Lee and W.H.Pang," A Brushless DC Motor Speed Control System Using Fuzzy Rules," Fifth International Conference on 26-28 Oct.1994 page(s):101-106.

[6] Tzuen-Lih Chern, Jerome Chang, and Greeng-Kwei Chang," DSP-Based Integral Variable Structure Model Following Control for Brushless DC Motor Drivers," IEEE Trans. On Power Electronics,vol. 12, no.1,Jan. 1997 page(s):53-63.

[7] E.M. Ramzy,"Robotic Manipulator Arm Control Using the Adaptive Gain Scheduling PID Controller",M.Sc. thesis, Cairo University, Cairo, 1996.

[8] S.G. Kong and B. Kosko, "Adaptive Fuzzy Sustems for backing up a Truck and Trailer", IEEE Trans. On Neural Network, Vol.3, No.2, March 1992.

[9] Li-Xin Wang, "Adaptive Fuzzy Systems and Control Design and Stability Analysis", Prentice-Hill, Englewood Cliffs, New Jersey, 1994. 